\title{
A radioimmunoassay method for detection of DNA based on chemical immobilization of anti-DNA antibody
}

\author{
Seoung-Kyo Yoo', Myungok Yoon', \\ UI Jae Park', Hyon Soo Han², Jeong Hee Kim \\ and Hyun Jin Hwang ${ }^{1,4}$ \\ ${ }^{1}$ Department of Chemistry, Kyung Hee University, \\ Seoul 130-701, Korea \\ ${ }^{2}$ Korea Atomic Energy Research Institute, Taejon 305-353, Korea \\ ${ }^{3}$ Department of Biochemistry, College of Dentistry, \\ Kyung Hee University, Seoul 130-701, Korea \\ ${ }^{4}$ Corresponding author: Tel, 82-2-961-0298; Fax, 82-2-969-3467; \\ E-mail, hjhwang@nms.kyunghee.ac.kr
}

Accepted 12 July 1999

Abbreviations: RIA, radioimmunoassay; ELISA, enzyme-linked immuosorbent assay; hCG, human chorionic gonadotropin; HAS, human serum albumin; EDC, 1-ethyl-3-[3-(dimethylamino) propyl] carbamide; NHS, $\mathrm{N}$-hydroxysuccinimide

\begin{abstract}
High selectivity provided by biomolecules such as antibodies and enzymes has been exploited during the last two decades for development of biosensors. Of particular importance are efficient immobilization methods for biomolecules in order to preserve their biological activities. In this study, we have evaluated immobilization strategies for an anti-DNA antibody on a self-assembled monolayer of $\omega$-functionalized thiols. The antibody was immobilized via peptide bond formation between the primary amines in the antibody and the carboxyl groups on the selfassembled monolayer. The peptide bond coupling was achieved by activating $\mathrm{COOH}$ groups on the surface through $\mathrm{N}$-Hydroxysuccimide (NHS)-ester formation, followed by acylation of $\mathrm{NH}_{2}$ group in the antibody. DNA binding activity of the immobilized antibody was examined by counting $\beta$ emission from ${ }^{35} \mathrm{~S}$-labeled DNA.
\end{abstract}

Keywords: anti-DNA antibody, DNA binding activity, immobilization, self-assembled monolayer, $\omega$-functionalized thiol

\section{Introduction}

One of the most important factors for precise diagnosis of various diseases is detecting the target molecules, possibly pathogenic biomolecules in the early phase of the disease. Detecting biomolecules such as drug metabolites, hormones and proteins in very small quantity also has valuable importance in the evaluation of the treatment of various diseases. Because the immunologic methods of quantifying concentrations of biomolecules provide exquisite sensitivity and specificity, immunoassay methods have become standard techniques for both research and clinical applications (Abbas et al., 1997; Roitt et al., 1998). Radioimmunoassay (RIA) and enzyme-linked immunosorbent assay (ELISA) are used extensively for quantification of antigens in solution. In RIA, the molecule to be detected is labeled with a radioisotope. Thus, the quantity of the molecule is measured by photoemission in a scintillation counter. In ELISA, the molecule to be detected is covalently coupled to an enzyme, thus, it can be quantified by determining the intensity of color development by the enzyme with a spectrophotometer. These immunoassay methods are easy to use and efficient because a large number of samples can be processed at the same time. In addition, the RIA technique is highly sensitive for detecting antigens and antibodies, and is economical because it uses small amounts of reagents. Various kits based on the immunoassay technique are arailable for the trace level detection of biomaterials. However, these kits are expensive, and often do not yield reproducible data.

Recently, there is increasing interest in the immobilization of biomolecules based on a surface-derivatization method using spontaneous self-assembled monolayer formation of thiol molecules (Mirsky et al., 1996; Rickert et al., 1996; Madoz et al., 1997). Immobilization of a number of different antibodies such as anti-hCG (human chorionic gonadotropin) (Duan and Meyerhoff, 1994; Klonisch et al., 1996) and anti-HAS (human serum albumin) antibody (Welsch et al., 1996). etc., has been tried based on the chemical coupling method using EDC (1ethyl-3-[3-(dimethylamino) propyl]carbamide) alone or NHS ( $N$-hydroxysuccinimide) with EDC at different coupling conditions. Development of such new immobilization methods for preparation of solid phase antibody is critical in various immunoassay methods such as ELISA and RIA as well as various biosensor techniques.

In this study, chemical immobilization of antibody on a solid surface has been developed based on a wellknown biochemical coupling method that has been used for solution phase coupling. We chose anti-DNA anti- 
body as a model system for immobilization because of the increasing importance of detecting DNA in many research and clinical fields. We used a lower concentration of antibody in immobilization reaction compared to those used in other reports (Duan and Meyerhoff, 1994; Welsch et al., 1996; Berggren and Johansson, 1997), demonstrating higher efficiency of immobilization. Anti-DNA antibody was immobilized on a solid surface that was chemically derivatized by using self-assembled monolayer formation of thioctic acids, and we confirmed the activity of chemically immobilized anti-DNA antibody. Therefore, we present here the selective detection of DNA in very small quantity with the immobilized antiDNA antibody.

\section{Materials and Methods}

\section{Materials}

Chemicals for immobilization reaction are purchased from the following sources; (D,L)-thioctic acid (Aldrich, USA), 1-ethyl-3-[3-(dimethylamino) propyl]carbamide (EDC) (Sigma, USA), and $\mathrm{N}$-hydroxysuccinimide (NHS) (Pierce, USA). Gold-coated polyvinylidene fluoride film (Au thickness, 1,000 Å) was purchased from Measurement Specialties Inc., USA. Mouse anti-DNA monoclonal antibody was purchased from Chemicon International, USA. Anti-DNA antibody was produced by using calf thymus DNA as an immunogen and this antibody recognizes both single- and double-stranded DNA. Taq polymerase, and deoxy nucleotide mixture (dNTP) were obtained from Takara, Japan. $\left[\alpha^{-35} \mathrm{~S}\right.$ ] d-ATP $(1,250 \mathrm{Ci} /$ mmole) and scintillation cocktail solution were purchased from NEN, and ICN, USA, respectively. Universal and reverse primers were synthesized from Bioneer, Korea. Other chemicals were purchased from Sigma, USA, or from other common sources.

\section{Immobilization of Anti-DNA antibody}

Gold film was carefully cleaned with Piranha solution $\left(30 \% \mathrm{H}_{2} \mathrm{O}_{2}\right.$ : concentrated $\left.\mathrm{H}_{2} \mathrm{SO}_{4}=1: 3\right)$ for $1 \mathrm{~min}$. The film was soaked in $10 \mathrm{mM}$ thioctic acid in absolute ethanol for overnight, rinsed with ethanol and dried. Then, it was immersed in $20 \mathrm{mM}$ NHS and $20 \mathrm{mM}$ EDC in anhydrous ethanol for $2 \mathrm{hr}$ to activate the $\mathrm{COOH}$ groups on the surface and rinsed with ethanol. Activated film was incubated with diluted anti-DNA antibody $(1: 1,000$ dilution in MES buffer, $\mathrm{pH} 7.0$ ) at $4^{\circ} \mathrm{C}$ for overnight, and the film with immobilized antibody was incubated in $5 \%$ ethanolamine for $10 \mathrm{~min}$ to deactivate unreacted carboxyls.

\footnotetext{
Radioactive labeling of DNA by polymerase chain reaction (PCR)

We used bacterial plasmid DNA, pBluescript as a template DNA. Plasmid DNA was purified from E. coli strain
}

DH5 $\alpha$ transformed with pBluescript plasmid DNA as described in Sambrook et al. (1989). Concentration of DNA was measured by UV spectrophotometer (Pharmacia Biotech Ultraspec 2000, USA). A typical PCR mixture contained $200 \mathrm{ng}$ of DNA, $0.4 \mu \mathrm{M}$ each of universal and reverse primer, $50 \mu \mathrm{M}$ of dNTP, $2.5 \mathrm{U}$ of Taq polymerase and 0.1 vol. of $10 \mathrm{x}$ buffer in $100 \mu \mathrm{l}$ final volume. For labeling purpose, $2 \mu \mathrm{l}$ of $\left[\alpha^{-35} \mathrm{~S}\right] \mathrm{d}$-ATP was added to the reaction mixture. The reaction mixture was heated to $94^{\circ} \mathrm{C}$ for $5 \mathrm{~min}$. The PCR profile was $94^{\circ} \mathrm{C}$ for $30 \mathrm{sec}, 50^{\circ} \mathrm{C}$ for $1 \mathrm{~min}$, and $72^{\circ} \mathrm{C}$ for $30 \mathrm{sec}$ for 30 cycles, followed by $72^{\circ} \mathrm{C}$ for $10 \mathrm{~min}$. We always ran labeling reactions with the standard control reaction side by side. After PCR, an aliquot of the control reaction was analyzed on $1.2 \%$ agarose gel containing $0.5 \mu \mathrm{g} / \mathrm{ml}$ ethidium bromide to confirm the generation of PCR product.

\section{Immunoassay}

Antibody-immobilized film was blocked with $5 \%$ bovine serum albumin for $30 \mathrm{~min}$, and washed with TBST (20 $\mathrm{mM}$ Tris, $\mathrm{pH} 7.8,150 \mathrm{mM} \mathrm{NaCl}$, and $0.05 \%$ Tween-20) for 3 times for $3 \mathrm{~min}$ each. Then, the labeled DNA was added to the film and incubated for 2 hrs at room temperature. After incubation, the residual solution was discarded and the film was washed for 3 times for $3 \mathrm{~min}$ each. The film was dried and the $\beta$-emission was measured with a scintillation counter (Wallac, system 1400, EG\&G Co., Finland).

\section{Results and Discussion}

Gold film was chosen as a solid support for immobilization of anti-DNA antibody in order to use the wellknown chemisorption reaction of thiols and disulfides (Finklea et al., 1987; Bain et al., 1989; Ulman, 1991; Zhong and Porter, 1995; Ulman, 1996). In this study, the gold surface was derivatized with thioctic acid, a $\omega$-carboxylated thiol. Immersion of film in the thioctic acid solution resulted in spontaneous formation of sulfur-gold bonds, thus a molecular monolayer of thioctic acid was formed on the surface of gold (Figure 1). NHS activates the carboxyl groups of the thioctic acids on the gold surface by forming NHS ester in the presence of EDC. The NHS-activated carboxyl group, produced in this method has much longer lifetime than the reaction intermediates formed with EDC alone (Hoare and Koshland, 1967; Grabavek and Gergely, 1990; Mirsky et al., 1997). These NHS ester-activated carboxyl groups readily react with primary amine groups of antibody by forming peptide bonds (see Figure 1). This final coupling step competes with the hydrolysis of NHS esters, the activated carboxyl groups. Thus, in aqueous solution, uncoupled NHS-activated carboxyl groups are deactivated by spontaneous hydralysis by water molecules. 


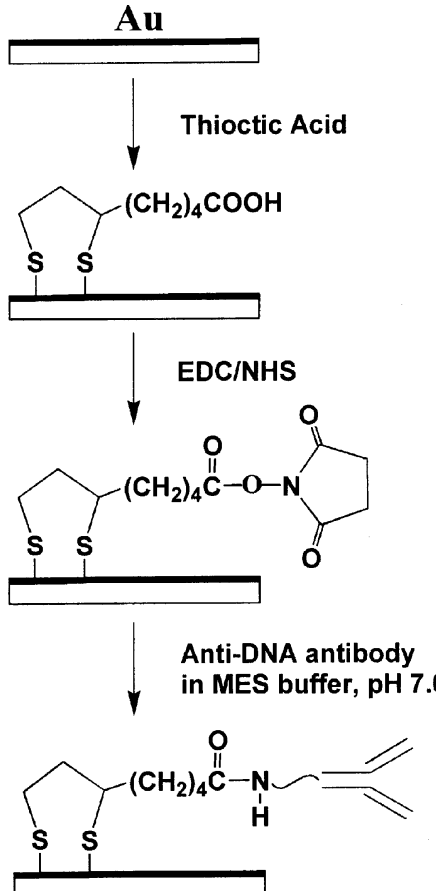

Figure 1. The immobilization scheme of the anti-DNA antibody. See Materials and Methods for details.

After the immobilization of the antibody, the film was further treated with $5 \%$ ethanolamine solution to complete the deactivation of unreacted carboxyls and minimize the generation of free carboxyl group.

The immobilized anti-DNA antibody was incubated with the antigen, which is the radioactively labeled DNA. The DNA used in this study was the PCR product of 229 bp containing the major portion of multiple cloning sites of pBluescript (see Materials and Methods for details). Figure 2 shows that the immobilized anti-DNA antibody has specific binding activity to DNA. The control film was prepared with a thioctic acid monolayer formation followed by coating with bovine serum albumin for blocking nonspecific binding. While the control film showed a low signal, the antibody-immobilized film exhibited significantly higher signals, up to 4 times as high as the control. Our data showed that even after chemical immobilization on to the solid surface, the antiDNA antibody retained the ability to bind specifically to the antigen DNA. The DNA bound to the immobilizedDNA antibody was stable during the exhaustive buffer wash whereas the radioactivity in the control was further removed.

It is noteworthy that the concentration of antibody used in this study $(\sim 50 \mu \mathrm{g} / \mathrm{ml})$ was about $20-40$ times diluted, compared to those used in previous experiments (1.0-2.1 mg/ml) (Duan and Meyerhoff, 1994; Welsch et al., 1996; Berggren and Johansson, 1997). This is important since the antibody concentration used in previous methods is not realistic in practical applica-

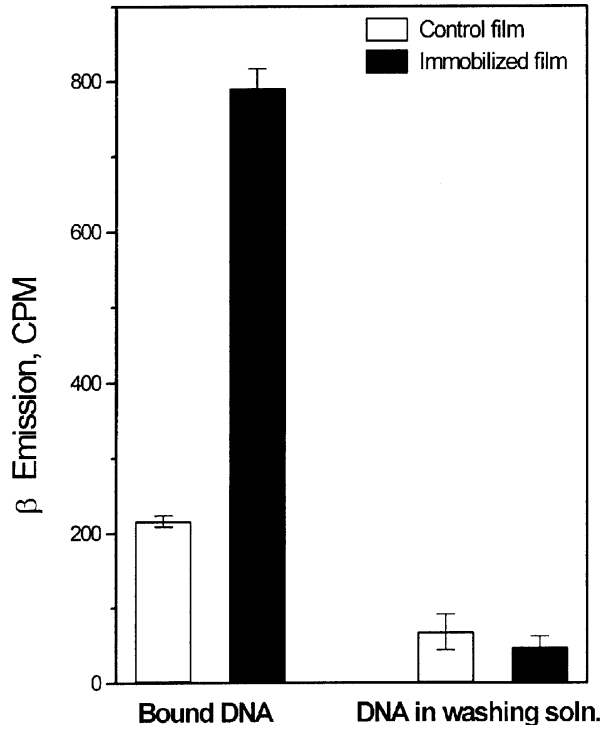

Figure 2. DNA-binding activity of the immobilized anti-DNA antibody. The radioactivity measured with the immobilized anti-DNA antibody $(\square)$ or with the control $(\square)$. The control film was prepared by using the same procedure but without the antibody immobilization step.

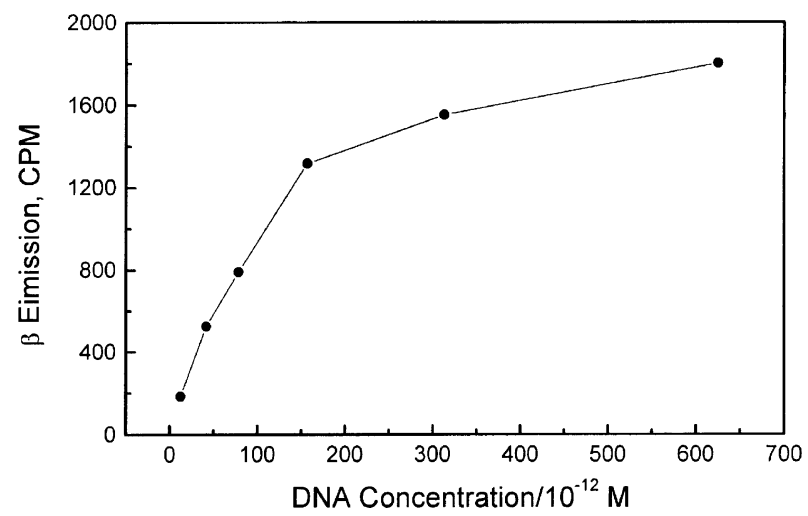

Figure 3. DNA concentration dependence of the DNA-binding activity of the immobilized anti-DNA antibody.

tions due to the high cost of antibodies. In the present study, the $\mathrm{COOH}$ groups on the surface were activated to form NHS-esters which have longer lifetime in aqueous solution (e.g. 2 hrs at room temperature, at $\mathrm{pH} 6.0$ ) (Grabarek and Gergely, 1990) than EDC-activated $\mathrm{COOH}$ groups (e.g. less than $1 \mathrm{sec}$ at room temperature, at $\mathrm{pH}$ 4.75) (Hoare and Koshland, 1967). Due to the longer lifetime of the NHS-activated $\mathrm{COOH}$, the coupling efficiency is increased dramatically. Therefore, the present scheme works efficiently in much lower antibody concentration.

Figure 3 shows concentration dependence of the binding signal between immobilized anti-DNA antibody and antigen DNA. In our study, the detection limit was estimated to be $\sim 10^{-11} \mathrm{M}$. In the concentration range of 1.25 to $15.7 \times 10^{-11} \mathrm{M}$, the binding signal showed a near linear dependence on the DNA concentration. When the 
concentration was higher than $1.57 \times 10^{-10} \mathrm{M}$, the binding of DNA to the immobilized antibody seemed to be saturated. We also tried immobilizing anti-DNA antibody at different $\mathrm{pHs}(\mathrm{pH} 6.0,8.0$, and 9.0), but the result obtained at $\mathrm{pH} 7.0$ gave $10-30 \%$ higher signal compared to the results obtained at other pHs (data not shown).

In this study, we have shown that the antibody can be immobilized on the solid surface by a chemical immobilization method with preservation of its binding activity. As an example, it was demonstrated that a selective and quantitative detection of DNA can be accomplished based on the solid-phase immobilization of anti-DNA antibody. Although the present detection scheme utilizes radioisotope labeling of DNA by using the PCR method, the same immobilization scheme can be easily adopted for other immunoassay methods such as ELISA as well as other various biosensor techniques based on electrochemical and optical detection methods. The fact that antibodies with different antigen specificities are known to possess a common skeleton structure suggests that the present immobilization method can be applied to other antibodies for selective detection of various antigens which are important for clinical and research purposes. We are currently further investigating optimal immobilization conditions using kinetic studies with varying $\mathrm{pHs}$ and $\mathrm{COOH}$ concentrations.

\section{Acknowledgement}

This study has been carried out under the nuclear R\&D program of Ministry of Science and Technology, Korea. H. J. H. acknowledges the Special Instrument Maintenance Funding from the Korea Science and Engineering Foundation. M. Y. is supported by a visiting scholarship grant from the Brain Pool Program of the Korean Federation of Science and Technology Societies.

\section{References}

Abbas, A. K., Lichtman, A. H. and Pober, J. S. (1997) Laboratory uses of antibodies, In Cellular and Molecular Biology $3^{\text {rd }}$ eds., pp. 59-65, Saunders, Philadelpia

Bain, C. D., Troughton, E. B., Tao, Y.-T., Evall, Y., Whitesides, G. M. and Nuzzo, R. G. (1989) Formation of organic thiols from solution onto gold. J. Am. Chem. Soc. 111: 321-335

Berggren, C. and Johansson, G. (1997) Capacitance measurements of antibody-antigen interactions in a flow system. Anal. Chem. 69: 3651-3657
Duan, C. and Meyerhoff, M. E. (1994) Seperation-free sandwich enzyme immunoassays using microporous gold electrodes and self-assembled monolayer/immobilized capture antibodies. Anal. Chem. 66(9): 1369-1377

Finklea, H. O., Avery, S., Lynch, M. and Furtsch, T. (1987) Blocking oriented monolayers of alkyl mercaptans on gold electrodes. Langmuir 3: 409-413

Grabarek, Z. and Gergely, J. (1990) Zero-length crosslinking procedure with the use of active esters. Anal. Biochem. 185: $131-135$

Hoare, D. G. and Koshland, D. E., Jr. (1967) A method for the quantitative modification and estimation of carboxylic acid groups in proteins. J. Biol. Chem., 242: 2447-2453

Klonisch, T., Panayotou, G., Edwards, P., Jackson, M., Berger, P., Delves, P. J., Lund, T. and Roitt, I. M. (1996) Enhancement in antigen binding by a combination of synergy and antibody capture. Immunology, 89: 165-171

Madoz, J., Kuznetzov, B. A., Mersrano, F. J., Garcia, J. L. and Fernandez, V. M. (1997) Functionalization of gold surfaces for specific and reversible attachment of a fused $\beta$-galactosidase and choline-receptor protein. J. Am. Chem. Soc. 119: 10431051

Mirsky, V. M., Krause, C. and Heckmann, K. D. (1996) Capacitive sensor for lipolytic enzymes. Thin Solid Films 284/285: 939-941

Mirsky, V. M., Riepl, M. and Wolfbesis, O. S. (1997) Capacitive monitoring of protein immobilization and antigen-antibody reactions on monomolecular alkylthiol films on gold electrodes. Biosensors and Bioelectronics 12: 977-989

Rickert, J., Gopel, W., Beck, W., Jung, G. and Heiduschka, P. (1996) A mixed self-assembled monolayer for an impedimetric immunosensor. Biosensors and Bioelectronics 11: 757-768

Roitt, I., Brostoff, J. and Male, D. (1998) Immunological techniques, in Immunology, $5^{\text {th }}$ ed., p381-395, Mosby, New York

Sambrook, J., Fritsch, E. F. and Maniatis, T. (1989) Molecular cloning, a laboratory manual, Cold spring harbor press, Cold spring harbor

Ulman, A. (1991) An introduction to ultrathin organic films: from Langmuir Blodgett to self-assembly, Academic Press, Boston, MA, USA

Ulman, A. (1996) Formation and structure of self-assembly monolayers. Chem. Rev. 96: 1533-1554

Welsch, W., Klein, C., Schickfus, M. V. and Hunklinger, S. (1996) Development of a surface acoustic wave immunosensor. Anal. Chem. 68(13): 2000-2004

Zhong, C. J. and Porter, M. D. (1995) Desingning interfaces at the molecular level. Anal. Chem. 709A-715A 